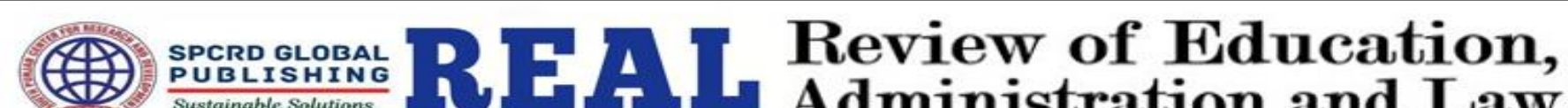 \\ Journal homepage: http://real.spcrd.org ISSN (Print): 2708-1788 ISSN (Online): 2708-3667
}

\section{The Effect of Google Search Volume Index on the Stock Market Excess Returns. Evidence from Listed firms in Pakistan stock Exchange}

\author{
a Bushra Ayaz, ${ }^{\mathrm{b}}$ Hamid Ullah, ${ }^{\mathrm{c}}$ Muhammad Kamran Khan, ${ }^{\mathrm{d}}$ Shahid Jan \\ a Islamia College University, Peshawar, Pakistan. \\ ${ }^{\mathrm{b}}$ Islamia College University, Peshawar, Pakistan. \\ Email: hamidullah@icp.edu.pk \\ c Bacha Khan University, Charsadda, Pakistan. \\ Email: drkamrankhan@bkuc.edu.pk \\ ${ }^{\mathrm{d}}$ Islamia College University, Peshawar, Pakistan.
}

\begin{tabular}{|c|c|}
\hline ART & \multirow{10}{*}{$\begin{array}{l}\text { ABSTRACT } \\
\text { The aim of this study is to examine whether google search volume index } \\
\text { (GSVI) as a tool of investor's attentions can be of great used to forecast } \\
\text { stock returns. In this paper we answer the question whether "price } \\
\text { pressure hypothesis "would hold true for Pakistan stock markets. The } \\
\text { nature of current study is quantitative in nature and research design is } \\
\text { used to test the hypothesis developed to examine google search volume } \\
\text { index and stocks return behavior. We used balanced panel data for the } \\
\text { period from } 2003 \text { to } 2019 \text { for companies listed in Pakistan stock } \\
\text { exchange. In this paper, we use regression technique for econometrics } \\
\text { estimation. The results showed that high and a positive return is } \\
\text { associated with high google search volume. To be more accurate, we can } \\
\text { say that a google search volume index is an important and useful } \\
\text { predictor for both the directions and magnitude of excess returns. We } \\
\text { suggest that, this study will be helpful for the information of profitable } \\
\text { trading strategies. With this study, we complement all previous work } \\
\text { done in developed countries on the correlation between stock trading } \\
\text { behavior and search intensity by using more robust statistical } \\
\text { techniques and large sample size. }\end{array}$} \\
\hline His & \\
\hline & \\
\hline Avai & \\
\hline Keyv & \\
\hline & \\
\hline $\begin{array}{l}\text { Predictability } \\
\text { Stock Market }\end{array}$ & \\
\hline JEL & \\
\hline L14, & \\
\hline DOI & \\
\hline
\end{tabular}

(C) 2021 The authors. Published by SPCRD Global Publishing. This is an open access article under the Creative Commons Attribution-

NonCommercial 4.0

Corresponding author's email address: drkamrankhan@bkuc.edu.pk

\section{Introduction}

The Rome had the first stock market in whole world, it was established in the second century BC as the Roman Publican. Basic information was needed for the decision making and large number of courier groups were considered by the Publican for gathering the information from the locals about their needs for providing different services to the public throughout the Roman Empires. Hence, two thousand years later, there were major changes in the gathering of information regarding prices of equities and assets. The way of delivering message has been change over the years like from scribes to 
digital media have transformed from telegraph to telephone and at last ultimately the internet. In present time, businesses use internet for different information and it plays a very significant role. Nowadays, it has become much easier to access any information through different search engines. However, businesses spent on designing a perfect search engine which help them to scroll web and index for the searches based on the volume of traffic.

The most researched subject in finance is prediction of stock returns. Researchers have different perspective regarding stock market movement that it is not possible to predict and predictability about the understanding of the financial markets. Researchers focus have changed with the passage of time. Therefore, Finance researchers are more concerned about the presence of positive indicator in stock prices trends for the investors' attention.

Market price is the reflection of available information according to the assumption of asset pricing model (Fama, 1976). The available information in the market for the investor to analyze equity markets have limited attention constraints, that's why they emphasized only on information of their interest. It means that investor attention should be related with market activities. Attention is a scarce cognitive activity due to which investors have limited information access (Khaneman, 1973). Stock prices and liquidity is related to investors' attention (Merton, 1987). According to the previous literature new information which occurs randomly are guiding stock.

Regardless of the sentiment and mood of individual investor can be used as an indicator for the idea of using investor attention as stock prices of investor attention. The utmost component to liquidity and stock prices for investor recognition was first examined by (Merton 1987). The theoretical framework of asset pricing consist of investor attention has been presented by ((Merton, 1987) (Peng \& Xiong, 2006) (Sims 2003) ( Hautsch et al., 2011).The returns of investor attention of some assets as a feedback loop was argued by Vozlyublennaia (2014).Nevertheless, the time duration of high turnover rates and price oscillations can be attributed to dissimilar factors of investor attention (Da, Engelberg, \& Gao, 2011).

Past studies revealed, the investor attention can be measure indirectly like, such as trading volume (Gervais, Kanie, \& Mingelgrin, 2001), abnormal returns (Barber \& Odean, 2008), or advertising expenses (Grullon, Kanatas, \& Weston, 2004) ( Lou, 2014), news and headlines related with different stocks (Yuan, 2015) that could be influenced through dissimilar factors of investor attention . Furthermore, the search volume index (SVI) can be a better proxy for investor attention presented by Da et al., (2011). Online search activities have the quality to predict about stock return as (Joseph, Wintoki, \& Zhang, 2011) have investigated that the search increase in the previous period can forecast increased volume and abnormal stock returns. So, search behavior of investors is represented by Google's search volume. Moreover, when people are interested to invest in the stock and pay attention to it, definitely they search for a specific stock.

As the Google records all the search data for the search terms, so the google trends tools helps to download the past search terms. However, google search engine is most popular on the internet. Google Trends is use as a tool in their research by researchers (Ginsberg et al., 2008) (Pelat, Turbelin et al., 2009; Carneiro \& Mylonakis, 2009).

Mixed results for the Financial markets have been forecasted based on google trends data .There is no correlation exist among search volume and stock returns .However, google search data is useful in predicting trading volume by Preit et al., (2013).Portfolio diversification effect on the google search 
volume has been studied by the Kristoufek (2013) and find that diversification strategy can be used for the stocks with high intensity for search is to make a portfolio dominant as a benchmark index for the portfolio of equal weights.

Impact of investors sentiment is the focus of researchers (Baker \& Wurgler, 2006).Data available in different articles of news, Twitter and Wikipedia((Takeda \& Yamazaki, 2006) (Bollen, Mao, \& Zeng, 2011) (Moat et al., 2013) are usually which researchers relied upon. Direct measure for the investors' attention uses GSVI. (Da et al., 2011)recent literature supports 'price pressure hypothesis' or attention theory and further reveal that it is significantly related with positive stock returns with shift in volume (Joseph et al., 2011; Bank, Larch, \& Peter, 2011; and Vlastakis \& Markellos, 2012). GSVI can be used for forecasting financial index and investigating the finance based keywords strategy, as discrete based keywords does not outperformed strategy (Challet \& Ayed, 2013).

Therefore, we investigate the investor attention effect on Google search intensity for a developing stock market and to predict potential future stock returns has been studied. In addition, our study enhances understanding of the investor about the useful information to predict stock returns using GSVI.

\section{Literature Review}

For a very long time, the attention measures have been in news around the world. For the investor measurement, GSVI is a sort of new topic. Most of the work on use of search volume index (SVI) and considered investor attention as a proxy has been done by (Da et al., 2011) and hence, Russell 3000 stock tickers weekly SVI values and the impact of volatility of prices of stock on SVI has been analyzed.

The inference drawn from efficient market hypothesis depicts that the stock prices shed light on all the relevant information. Financial anomaly based escalated and researches has directed their attention towards actions that were impossible to be explained by the hypothesis and reasons for the market efficiency violation. The theories of security proposed by Hirshleifer and Subramanyam(1998); (Barber \& Odean, 2008), Shleifer and Vishny(1998) and Daniel, provide explanation of psychological biases and anomalies and analyze the varieties of response for the information for good-bad news. The investor attention and asset pricing have a visible role in different studies.

Psychological biases is one of reason for restricting the focus of results from the information process. The appropriate way is to check the impact of trading on investor attention in response to information. As stated by Shleifer and summers (1990), investors are irrational so variations in investor sentiment are essential factors in price determination. Had investor been completely rational, they would have recognized that noise trading is devastating. Arbitrage has its drawbacks and risks. Arbitrageurs and noise traders are two groups to identify the investors. Arbitrageurs are not fully accountable for investor sentiment movements which affect prices.

Recent researches in behavior finance literature indicates an investor desire to assert pricing. Various methods are used to quantify investor attention such as advertising expenditure, promotional spending, extreme returns, and media coverage and consumer confidence.

According to Merton,1987 the "investor recognition hypothesis "tells us about the investors who are interested in the new information of stock which they intend to buy. In addition to the asset-pricing models, literature suggests two well-known theories founded on the efficient market hypothesis 
highlighting the association between stock prices and investor attention, "investor attention hypothesis" and "attention theory" or "price pressure theory". Attention is indeed the main factor in selection of stocks. Due to insufficient resources and time to analyze the variety of stock, the "Attention theory" delineates that individual investors' attention are inclined to purchase large number of stocks which results in trading volume and abnormal returns

Hence, the empirical studies that are in accord with "attention theory", have been demonstrated the association between investor attention and stock-price trends. Like for instance, the description in newspaper like New York Times, a small biotechnology company, could lead to a high impact on the company's stock values. The ads of Super Bowl broadcasts (1969-2001) had a positive impact on the stocks of the firm. Likewise, the Project X of Japanese has been broadcasted for the upturn stock prices of the companies was observed by Takeda and Yamazaki.

The attention effect drives the transitory price pressure theory. There are currently two empirical philosophical mechanism for the understanding of investor attention that drives price pressure: firstly the asymmetry of the choices hypothesis (Barron and Erev, 2003) (Fox and Hadar, 2006) (Hertwig et al., 2004) (Lanz et al., 2010) and secondly the information discovery hypothesis (Liao et al., 2011) ( Wang and Qian, 2015).According to Liao et al.,(2011) the information discovery hypothesis, debate about the asymmetry information amid investors to help mitigate the newly available information abundantly .Stock related information is accessible to investor through google search and trim down asymmetry information. As Hertwig et al., 2004, reflect that the prospect theory gives choices to asymmetry hypothesis, to consider description to make decision since individuals make preferences as if they highly consider the possibilities of occasional events. Hence, due to the probability of occasional events for individual to make decision from their experiences. Therefore, individual access the information sources that offer the positive aspect of uncertain prospects, they usually don't hesitate to take risks considering it easy. However, they will be more thoughtful in taking risks if they utilize their experiences in decision making. Accordingly, it has been observed that the GSVI helps individual investors to minimize disproportionateness regarding information selection while they decide about their investments.

A numerous study conducted on how investor sentiment influences security prices. The etymology of investor sentiment is described by (Baker \& Wurgler, 2006) as exogenous, impacting security market trading trends and identifying that investor sentiment is very complex to arbitrate. Two main views are cited to describe how investor sentiment affects security pricing. As stated by Merton (1987) firms that draw less investor attention leads to higher returns an account for insufficient diversification. "Attention theory" proposed by (Barber \& Odean, 2008) and states that by considering short term investors who are the main buyers of stocks with grabbing factor of attention due creates buying pressure of uninformed retail investing ( Bank et al.,2011 ) also found the association with trading volume and stock liquidity.

There is a scarcity of studies that emphasize on the association between stock trading and online search. (Da et al., 2011) were the first to evaluate the advantage for application of financial data in Google searches, wherein they suggested that GSV1 can be used as a direct measure for the cumulative searches, for indirect proxies for turnover, news, extreme returns, and advertising expense for investor attention They demonstrate that GSV1 captivates the attention of retail investors for the hypothesis testing presented by (Barber \& Odean, 2008) for induced price pressure.

Ticker stock symbols were used as keywords in Google Trends by (Da et al., 2011) to show GSV1 
and online ticker searches are having a positive association with excess returns of stocks that were included in S\&P500 from 2005 to 2008 and Russell 3000 from 2004 to 2008 . (Bank et al., 2011) considered name of a company rather than the ticker symbol and obtained the GSV1 and presented the positive response with stock liquidity and trade activities with search queries. Similarly, (Vlastakis \& Markellos, 2012) depicted a positive relationship with volatility and the volumes shifts for 30 major stocks information that were traded on the NASDAQ and NYSE. Whereas the Google searches neither have a relationship with the contemporary nor are able to give a prediction of the future excess returns, but they could forecast the increase in volatility and trade Kim et al., (2018). They find that, instead of current trading activity Google searches futuristic.

The two utmost problems that arise by using the name of company has been discussed by (Da et al., 2011) . The first one is that the investors uses search engines to have different new information of the company name may not be related with investment purpose or decision making. The Second one is that there is possibility to spell the company name in different ways. Vlastakis and Markellos (2012) has overcome such problem by assuming that components which are least interest to investors can be dispose of by data pre-processing. Google Insights can be used for the search volumes.

It was investigated, the "price pressure hypothesis" would apply to the Pakistani stock market. At present, the latest data from 2003 to 2019 has been gathered for analysis. The most popular search engine in Pakistan has been Google with about 70\% of Pakistan's market search share. The Google users are the representative of the investor population in Pakistan. Further, it is under study that whether the company names can be used for the forecasting of weekly stock returns for individual firms.

US stock market is examined in several studies. GSVI considered as a direct proxy of investor attention for stock ticker, proposed by (Da et al., 2011) introduce that attention can be quite often captured by search volume than other attention proxies. The retail investor attention and volatility of stock market relationship was shown by Dimpfl and Jank (2016). And they conclude that a strong simultaneous movement exists among them. The volatility increases in the next day is caused by greater number of search volumes. Mondria and $\mathrm{Wu}$ (2011) have proposed the newness in the measure of asymmetric attention that can investigate the modification among resident and nonresident investors attention for using search queries in stocks of S\&P500. However, they explained that the companies which get disproportionate attention among various investors including all local and non-local investors tend to have protracted portfolio and abnormal returns. The relationship amid indexes and investor attention enactment has been measured by GSVI was explored by Vozlyublennaia (2014). The study describes that in the short-term attention affects performance of indexes. Contrary to this finding, in the long term, unusual returns impact attention significantly. The result depicts the significant interaction effects between investor attention and lagged return values, which show that predictability of index returns can be affected by attention. The market efficiency can be improved by increasing investor attention by lowering down return predictability.

In latest studies, the investor attention has been used as a proxy for GSVI. Therefore (Da et al., 2011) have suggested the direct proxy of investor attention for the stock ticker of GSVI and introduce that more attention is captured by search volume than indirect attention proxies, and provides a measure of individual investor attention. Therefore, the concept of price pressure due to attention is supported by (Barber \& Odean, 2008) . However, (Joseph et al., 2011) state that online searches provide a prediction in the volumes shifts and stock returns in such a way that its allied with the difficulty of arbitrage of a stock in a positive way. 
GSVI has been used in few research studies that investigate among the non-US stock markets and investor attention. In France, the trade activity and volatility has been checked for the effect of investor attention by Aouadi et al., (2013).The authors indicated the significant correlation for trading volume and investor attention and that the control of crisis has major effect on stock market volatility and illiquidity .Tantaopas, Padungsaksawasdi and Treepongkaruna (2016) used GSVI to observed the association among stock return, shifts in volume, investor attention and volatility for indexes of AsiaPacific equity market in one-way causation and variations in market variables cannot be overlooked as it bring changes in the attention as concluded by the authors. The authors mention about the presence of attention is of utmost importance for the market to predict returns, and that the market depicts the asymmetric relation for the trends and attention. Baidu.com has been used as a search volume index by Ying et al., (2015) to investigate the investor attention in China and determine that investor attention is correlated positively to stock returns. The results conclude that after the second week the effect of attention is reversed but within a year its fleeting influenced cannot be entirely reversed. Institutional ownership can reduce the fleeting influence and therefore, reversals causes increase. Huang, Qiu and $\mathrm{Wu}$ (2016) used web stock message board for the investors in China to investigate local bias. The result concluded that more attention is being paid to local stock investors as compared to non-locals, besides this partiality is superior, non-CSI 300 stocks, specifically stocks and low turnover.

Very less is investigated about the Turkish stock market for investor sentiments. The impact of sentiments of individual investor on Istanbul stock exchange10o index volatility and stock returns in monthly summer confidence index was examined by Sayim and Rahman (2015). Proxy used for the investor sentiment as a residual for regressing trading volume as a standard for stock indexes of macro variables and concluded that the impact of earning shocks are at peak during different sentiment periods was conducted by Uygur and Tas (2014). In literature (Bekaert \& Harvey, 2002) (Muradoglu \& Unal ,1994) found that developing markets are lower in competence in information process. The investor sentiment are maintained in strong markets was showed by (Brzeszczynski, Nski,Gadki and $\operatorname{Kutan}(2015)$.

\section{Research Methodology}

Following the Da et al., (2015) the investor sentiment can be measure through internet search behavior. GOOGLE is top searched engine all over the world and therefore, with the help of Google Trends provides diverse search terms for GSVI. The investors enter search terms into Google Trends, and it helps them about the previous detail history for that term, which has been scale by the timeseries maximum (i.e. scalar).Hence, constructing a list of search terms that explores sentiment towards economic conditions has been proposed by (Da et al.,2015). Google Trends provides GSVIs either on a daily or weekly basis (Da et al., 2011).

In the paper, we have investigated the association between google search index for investors and stock trading behavior. The trend in trading volume data for each available stock has been change to detrended volume from original volumes. Takeda and Yamazaki, (2006) and Bijl et al., (2016) have used econometric estimation of regression which was source of motivation for us. The data set consists of significant fixed effects on regression models due to Hausam test (Hausman, 1978)

Following is the baseline specification:

Excess return $_{t}=\alpha+$ Lagged Excess return1 to $5+\Delta$ SGSVI1 to $5+$ Detrended Volume1 to $5+$ Past week volatility + Past 5 week volatility + et. 
Three interaction variables have been added to the baseline specification The trading volume of predictive value or GSVI depend upon the positive or negative news of a company on search day and it has been proxy as return in positive or negative way.

Excess return $_{t}=\alpha+$ Lagged Excess return 1 to $5^{+}$Lagged $\Delta$ SGSVI1 to $5+$ Detrended Volume 1 to $5+$ Past week volatility + Past 5 week volatility + Volume x Return t-1 + SGSVI t-1 x Volumet-1 + SGSVIt-1x Returnt-1 + عt.

\section{Google Search Volume Index}

Anyone can search any type of information from the market leading search engine GOOGLE. As SVI is easy accessible for any type of downloadable information over time for any type of searches due to the merging of google insights and trends in the year of 2012.Google search engine does not provide data in absolute terms while specific keywords are looked for, rather it is value relative because of its dependence on the searches in specific time period. The relative value is always normalized for search terms as the volume of searches fall within o (i.e.when search volume do not meet specific level in a period) and 100 (i.e. when search volume has highest level met).

Google trends tells us about the total number of searches for a specific company name over time. We have gathered company wise GSVI data for Pakistan. Therefore, GSVI is use for ticker searches as many abbreviations are in ticker commonly. Search volume index is popularly used for a company name.

We can calculate GSVI(SGSVI) as follows:

$$
\mathrm{SGSVI}_{t}=\frac{\mathrm{GSVI}_{t}-\frac{1}{n} \sum_{i=1}^{n} \mathrm{GSVI}_{i}}{\sigma_{\mathrm{GSVI}}},
$$

Hence $\mathrm{n}$ indicates the number of observations weekly and $\sigma$ GSVI indicates the full sampled std dev of time series.

Some of the significant attributes of GSVI are: Firstly, GSVI is the number of searches of any particular keyword conducted within same time horizon. Secondly, SVI is the weekly keyword searches that is scaled by its time series average and has value within o and 10o.Thirdly, GSVI tells us about the relative number of searches effectively. Fourth, as GSVI does not increase the frequency of particular keyword search. Fifth, so GSVI for weekly based searches for a particular time period can be highest if it takes the value of 100. Sixth, as the GSVI is calculated by the google so its data can be slightly different for the particular keyword as its downloaded during different time.

\section{Excess Return}

As Russell had been analyzed 3000 stocks during period of 2004 to 2008.Hence,there is increase in the Google search volumes for consecutive two weeks which lead to high return, then trend can be reverse by (Da et al., 2011).

Therefore, effect of GSVI on the overall market have focused by Chalet and Ahmad (2013), and (Preis, Reith, \& Stanley, 2010) as it differentiates from our focused that is individual excess return(Exc_Ret). We have considered opening of one week to the next week for weekly abnormal return. Following equation shows the calculation of excess return. 


$$
\text { Rt }=\text { Excess Return }=\mathrm{Rw}, \mathrm{t}-\beta \mathrm{RM}, \mathrm{W}, \mathrm{t}
$$

$\mathrm{R}_{\mathrm{t}}$ indicates total return.

Whereas RM, W indicates the weekly market return and ${ }^{\beta}$ indicates weekly rolling of the company.

Hence, the logic behind using first week opening price tells that the first opportunity for new information after GSVI release on Sunday. The weekly data is used due to availability for several years.

\section{Volatility}

Volatility has different phases at diverse timing with varied interest having uncertain definite pattern. Evidently, it all depends on investor requirement for information that increases during some definite phases. The relationship between volatility, returns and investors sentiments has been analyzed by Lee et al., (2002). Moreover, Google sentiment can be a good index, not only for different investment strategies, but also for Pakistani markets explaining the return volatility. Wang et al., (2006) has focused on the predictive power of investor sentiment along with the restricted power on stock volatility. The investor sentiment has a significant effect on stock market returns and their volatility by Honcoop and Lehnert (2007). However, transformation in the Google searches for a specific keywords can anticipate volatility in the foreign currency market has been found by Smith(2012).Moreover, the Google search volume index for the specific keywords like economic crisis and financial crisis is significantly associated to the week ahead volatility for different currencies.i.e.,5 currencies. Smith (2012) also concluded that the Google search volume index for the keyword like recession is also significantly associated to week ahead volatility for five currencies.

The largest stocks traded in the NASDQA and NYSE for the Google search volume index and volatilities have been studied by (Vlastakis \& Markellos, 2012) furthermore, their study finds the significant relationship with volatility and to the volume of stocks traded.

Therefore, Volatility is calculated on the weekly base data.(Poon \& Granger, 2003) have assumed that the mean return of volatility in contrast with the standard deviation in the estimation is 0 .

$$
\sigma_{w, t}=\text { SHORTVOLAT }=\sqrt{\sum_{i=1}^{n} r^{2}}
$$

Where $\mathrm{n}$ denotes the number of trading days in a week

According to (Corsi, 2009 and Bijl, Kringhaug, Molnár, \& Sandvik, 2016) volatility has two variables short-term volatility and long -term volatility

$$
\sigma_{l, t}=\text { LONGVOLAT }=\frac{1}{5} \sum_{i=t-4}^{t} \sigma_{w, i} .
$$

\section{Trading volume}

Joseph et al., (2011) has found out that the GSVI can be used as a proxy for investor attention and to anticipate stock returns and trading volumes. Further they devise a factor of sentiment on 
Google search queries, suchlike to Dao et al, 2011, they found out that the ability of online ticker searches to anticipated future return of stocks and abnormal trading volume. Hence, the proved that Google searches represent ticker as measurement tool for the investors.

Conrad, Hameed, and Niden (1994); Glosten, Jagannathan, and Runkle (1993) have showed strong relation between volume and returns. According to (Campbell, Grossman, \& Wang, 1993) have used detrended volume

$$
\mathrm{VLM}_{t}=\log \left(\text { Volume }_{t}\right)-\frac{1}{12} \sum_{i=t-11}^{n} \log \left(\text { Volume }_{i}\right) .
$$

\section{Data Collection Techniques}

The sample in our data comprises of non-financial companies listed on Pakistan stock exchange (PSE). The data has been obtained from Yahoo! Finance, google trends and companies' online data. As SVI tells us the frequency of searches for a specific term scaled between o and 100 by its time series average as 100 represents the peak searches for a term. We considered balanced panel data from 2003 to 2019 observations of 200 companies which helps us for the weekly available data within two days due to time series since 2004 .

\section{Table 1 Variables Definitions}

\begin{tabular}{|c|c|c|}
\hline Variables & Explanation & Data source \\
\hline 1.GSVIPAKISTAN & $\begin{array}{l}\text { Google trend generates data on } \\
\text { weekly basis for stock ticker for } \\
\text { the google search volume index. }\end{array}$ & Google Trend \\
\hline 2.RETURNS (\%) & $\begin{array}{l}\text { The weekly based return of the } \\
\text { individual stock from the } \\
\text { opening of one week to the next } \\
\text { week }\end{array}$ & Companies report \\
\hline 3. TURNOVERS (mil) & $\begin{array}{l}\text { The trading volume of individual } \\
\text { stock in a week calculated in } \\
\text { millions. }\end{array}$ & \\
\hline 4.EXCESSRETURNS (\%) & $\begin{array}{l}\text { The individual stock excess } \\
\text { return weekly for the following } \\
2 \text { weeks }\end{array}$ & Author's calculation \\
\hline 5.SGSVIPAKISTAN & Standardized GSVIPAKISTAN & Author's calculation \\
\hline 6.STURNOVER & $\begin{array}{l}\text { Standardized total turnover of } \\
\text { stocks }\end{array}$ & Author's calculation \\
\hline 7.VLM & The detrended log volume is & Author's calculation \\
\hline
\end{tabular}




\begin{tabular}{|l|l|l|}
\hline & indicated by the trading volume & \\
\hline 8.SHORTVOLAT & Short term volatility & Author's calculation \\
\hline 9, LONGVOLAT & Long term volatility & Author's calculation \\
\hline 10.CHANGE_IN_SGSVP & $\begin{array}{l}\text { Change in standardized } \\
\text { GSVIPAKISTAN weekly. }\end{array}$ & Author's calculation \\
\hline
\end{tabular}

\section{Results and Discussion}

For the stationarity of data, we have performed Panel unit root tests which consists of the Breitung test (2000) augmented Dicky-fuller test, Levin et al.(2002) and the Phillips-Perrson test. Impact of change in the SGVI (Pakistan) excess return has been analyzed. The positive effect in last weeks has been noticed in SGSVI .(Preis et al., 2010) findings showed inconsistent with this positive effect and (Bijl et al., 2016) after financial crisis. Hence, SGSVI shows significant and positive effect in the weeks lag of fourth and fifth. High google search volumes predicts positive return in the first two weeks with consequent negative returns are presented in the work of (Da et al., 2011). Moreover, our results for Pakistan stock market also showed strong and positive returns.

The results of the predictor power of SGSVI shows high effect than the detrended volume. The effects are shown in column 3 about the detrended volume coefficients are significantly smaller than that of SGVI. The explanatory power of R2 has been improved. In totality, the outcomes of GSVI shows a better predictor of abnormal return as well as direction. Hence, domestic investor of google searches as users have higher excess return.

We have investigated the association between investors' attention and the stock trading behavior by using GSVI, and investigate whether online investors attentions effect the succeeding stock return. It can be used as a tool for the qualifications of relationship between variations in stock return and stock volume. In the result Bijl et al., (2016) and Joseph et al.,(2011) work on S\&P50o Stocks have shown same effect like the one exists in Pakistan stock market and hence, proved by (Barber \& Odean, 2008) a "price pressure theory" or "attention theory".

\section{Table 2 Descriptive Statistics}

\begin{tabular}{|c|c|c|c|c|c|c|c|c|c|c|}
\hline & Mean & Median & Max. & Min. & SD & Skewness & Kurtosis & Jarque-Bera & Prob. & Obs. \\
\hline 1.GSVIPAKISTAN & 40.43 & 40.00 & 200.00 & 20.00 & 27.94 & 0.44 & 4.40 & 404 & 0.00 & 20,940 \\
\hline 2.RETURNS (\%) & -0.02 & 0.47 & 474.47 & -433.49 & 22.97 & -24.49 & 442.24 & $234,000,000$ & 0.00 & 20,929 \\
\hline 3. TURNOVER (mn) & 2,747 & 2,049 & 244,740 & 0.29 & 4,434 & 42.43 & $2,079.79$ & $429,000,000$ & 0.00 & 20,940 \\
\hline 4.. FIRMSRETURN & 0.02 & 0.27 & $7 \cdot 49$ & -49.93 & 4.23 & -20.94 & 244.77 & $20,794,009$ & 0.00 & 20,929 \\
\hline 5. EXCESS RETURNS (\%) & -0.04 & 0.07 & 304.94 & -394.04 & 22.42 & -7.30 & 474.49 & $202,000,000$ & 0.00 & 20,909 \\
\hline 6.SGSVIPAKISTAN & 0.00 & -0.02 & 4.79 & -4.44 & 2.00 & 0.44 & 4.40 & 404 & 0.00 & 20,909 \\
\hline 7.STURNOVER & 0.00 & -0.44 & 47.90 & -0.79 & 2.00 & 42.43 & $2,079.47$ & $427,000,000$ & 0.00 & 20,909 \\
\hline 8.VLM & 0.00 & 0.00 & 2.90 & -4.27 & 0.49 & -0.97 & 9.99 & 27,774 & 0.00 & 20,909 \\
\hline 9.SHORTVOLATILITY & 3.74 & 4.37 & 433.49 & 0.00 & 22.30 & 44.40 & 749.72 & $279,000,000$ & 0.00 & 20,909 \\
\hline 10.. LONGVOLAT & 3.74 & 4.97 & $99 \cdot 47$ & 0.49 & 4.07 & 9.77 & 229.94 & $7,397,424$ & 0.00 & 20,909 \\
\hline 11.CHANGE_IN_SGSVP & 0.00 & 0.00 & $4 \cdot 74$ & -3.99 & 0.49 & 0.44 & 22.34 & 34,297 & 0.00 & 20,909 \\
\hline
\end{tabular}

Note: As descriptive table shows std-dev,Skew,Kurt and Jar-Bera statistic and its corresponding p-value. 
Table 3 Panel Data Stationarity Tests

\begin{tabular}{|l|l|l|l|l|l|l|l|l|}
\hline & \multicolumn{2}{|c|}{ Breitung test } & \multicolumn{2}{c|}{ ADF test } & \multicolumn{2}{c|}{ LLC test } & \multicolumn{2}{c|}{ PP test } \\
\hline & Statistic & Prob. & Statistic & Prob. & Statistic & Prob. & Statistic & Prob. \\
\hline 1. SVIPAKISTAN & -6.44 & 0.00 & 439.46 & 0.00 & -9.23 & 0.00 & 2019.4 & 0.00 \\
\hline 2. RETURNS & -6.61 & 0.00 & 3363.93 & 0.00 & -393.39 & 0.00 & 3961.94 & 0.00 \\
\hline 3. TURNOVER & -64.02 & 0.00 & 4126.40 & 0.00 & -113.22 & 0.00 & 4906.39 & 0.00 \\
\hline 4. VLM & -39.96 & 0.00 & 4666.40 & 0.00 & -123.69 & 0.00 & 4633.64 & 0.00 \\
\hline 5. EXCESSRETURNS & -6.10 & 0.00 & 3996.96 & 0.00 & -339.69 & 0.00 & 3496.62 & 0.00 \\
\hline 6. SGSVIPAKISTAN & -14.63 & 0.00 & 969.69 & 0.00 & -26.96 & 0.00 & 2019.42 & 0.00 \\
\hline 7. CHANGE_IN_SGSVIP & -29.16 & o.oo & 4291.94 & o.oo & -94.13 & 0.oo & 2293.90 & 0.00 \\
\hline
\end{tabular}

Notes: For the performance of stationarity of variables, Augmented Ducker-fuller test (1976), PhillipsPerron test(1998) and (Levin, Lin, \& Chu, 2002) tests are conducted.

Table 4 Impact of Google Search Volume on Excess Returns

\begin{tabular}{|c|c|c|c|}
\hline Variables & 1 & 2 & 3 \\
\hline \multicolumn{4}{|l|}{$\Delta$ Standardized } \\
\hline $\mathrm{GSVI}_{t-1}$ & $-0.041(0.128)$ & $-0.064(0.126)$ & $-0.086(0.122)$ \\
\hline \multicolumn{4}{|l|}{$\Delta$ Standardized } \\
\hline $\mathrm{GSVI}_{t-2}$ & $0.469^{* *}(0.148)$ & $0.448^{* *}(0.148)$ & $0.469^{* * *}(0.144)$ \\
\hline \multicolumn{4}{|l|}{$\Delta$ Standardized } \\
\hline $\mathrm{GSVI}_{t-3}$ & $0.462^{* *}(0.160)$ & $0.462^{* *}(0.149)$ & $0.426^{* *}(0.146)$ \\
\hline \multicolumn{4}{|l|}{$\Delta$ Standardized } \\
\hline $\mathrm{GSVI}_{t-4}$ & $0.628^{* * *}(0.148)$ & $0.660^{* * *}(0.146)$ & $0.689^{* * *}(0.144)$ \\
\hline \multicolumn{4}{|l|}{$\Delta$ Standardized } \\
\hline $\mathrm{GSVI}_{t-5}$ & $0.406^{* *}(0.124)$ & $0.440^{* * *}(0.122)$ & $0.282^{* *}(0.118)$ \\
\hline Excess return $_{t-1}$ & $-0.018(0.016)$ & $-0.018(0.014)$ & $-0.008(0.016)$ \\
\hline Exc_ret $_{t-2}$ & $-0.19^{* * *}(0.014)$ & $-0.19^{* * *}(0.014)$ & $-0.18^{* * *}(0.016)$ \\
\hline Exc_ret $_{t-3}$ & $-0.21^{* * *}(0.014)$ & $-0.21^{* * *}(0.014)$ & $-0.19^{* * *}(0.016)$ \\
\hline Exc_ret $_{t-4}$ & $-0.196 * * *(0.014)$ & $-0.19^{* * *}(0.014)$ & $-0.18^{* * *}(0.016)$ \\
\hline Exc_ret ${ }_{t-5}$ & $-0.008(0.006)$ & $-0.009(0.006)$ & $-0.008(0.006)$ \\
\hline Detrended volume $_{t-1}$ & $-0.684^{*}(0.266)$ & $-0.686^{*}(0.264)$ & $-0.268(0.198)$ \\
\hline Det_vol vo-2 $_{t}$ & $1.862^{* * *}(0.261)$ & $1.866^{* * *}(0.269)$ & $1.060^{* * *}(0.196)$ \\
\hline Det_ vol $_{t-3}$ & $1.840^{* * *}(0.268)$ & $1.848^{* * *}(0.268)$ & $1.264^{* * *}(0.192)$ \\
\hline Det_vol $t_{t-4}$ & $0.809 * * *(0.268)$ & $0.806^{* * *}(0.266)$ & $1.016^{* * *}(0.191)$ \\
\hline Det_vol ${ }_{t-5}$ & $-0.049(0.260)$ & $-0.111(0.269)$ & $-0.008(0.186)$ \\
\hline Past month volatility & $0.289^{* * *}(0.019)$ & $0.291^{* * *}(0.019)$ & $0.286^{* * *}(0.019)$ \\
\hline $\begin{array}{l}\text { Past } \quad 6 \text {-Month } \\
\text { Volatility }\end{array}$ & $-1.689^{* * *}(0.061)$ & $-1.69^{* * *}(0.060)$ & $-1.49^{* * *}(0.060)$ \\
\hline Volu $\times$ Return $_{t-1}$ & $-0.118(0.181)$ & & \\
\hline $\mathrm{SGSVI}_{t-1} \times$ Volu $_{t-1}$ & & $1.081^{* * *}(0.089)$ & \\
\hline $\mathrm{SGSVI}_{t-1} \times$ Return $_{t-1}$ & & & $0.002(0.012)$ \\
\hline Intercept & $4.820^{* * *}(0.119)$ & $4.626^{* * *}(0.118)$ & $4.819^{* * *}(0.119)$ \\
\hline R-square & 0.24 & 0.28 & 0.26 \\
\hline Month fixed effect & Yes & Yes & Yes \\
\hline $\mathrm{N}$ & 2660 & 2660 & 2660 \\
\hline
\end{tabular}

Notes: The table IV shows the results of PLS and FE with coefficients values marked with significance levels $10,5,1 \%$ as $*, * * * * *$ in the different rows, accordingly 


\section{Conclusion}

In this study, we have used search volume index data for the measurement of online search intensity to proxy for investors' attentions. The data is obtained from google for listed firms in Pakistan stock exchange for the period 2003 to 2019. The results of our study depict a significant return in the subsequent weeks like fourth and fifth due to high google search volume. The analysis of stock returns depicts that GSVI has greater effect than detrended volume. We observe that GSVI is a better forecaster for the magnitude of excess return and directions. We also found that a search volume has a positive and strong association with excess return. The finding of study suggests that for profitable trading strategies, the trends in the shifts of volume search data could be of great advantage, respectively. With the help of results, we come to conclusion, that there is association between GSVI and stock returns, but the weekly based data do not give clear signals of such relationship trend. Hence searched stocks show high returns on weekly based data in the current period and low returns in the following period, so it shows the association between search volume and returns are negatively weak. Moreover, there is no such proof that high frequency searched stocks always have significant returns in the subsequent periods. Past search volume does not give guarantee of high return in stock market. Hence, literature review clearly shows good signs of association between searches and stock returns.

\section{References}

Baker, M., \& Wurgler, J. (2006). Investor sentiment and the cross-section of stock returns. The journal of finance, 61(4), 1645-1680.

Bank, M., Larch, M., \& Peter, G. (2011). Google search volume and its influence on liquidity and returns of German stocks. Financial markets and portfolio management, 25(3), 239.

Barber, B. M., \& Odean, T. (2008). All that glitters: The effect of attention and news on the buying behavior of individual and institutional investors. The review of financial studies, 21(2), $785-818$.

Bijl, L., Kringhaug, G., Molnár, P., \& Sandvik, E. (2016). Google searches and stock returns. International Review of Financial Analysis, 45, 150-156.

Bollen, J., Mao, H., \& Zeng, X. (2011). Twitter mood predicts the stock market. Journal of computational science, $2(1), 1-8$.

Breitung, J. (2001). The local power of some unit root tests for panel data: Emerald Group Publishing Limited.

Campbell, J. Y., Grossman, S. J., \& Wang, J. (1993). Trading volume and serial correlation in stock returns. The Quarterly Journal of Economics, 108(4), 905-939.

Challet, D., \& Ayed, A. B. H. (2013). Predicting financial markets with Google Trends and not so random keywords. arXiv preprint arXiv:1307.4643.

Conrad, J. S., Hameed, A., \& Niden, C. (1994). Volume and autocovariances in short-horizon individual security returns. The journal of finance, 49(4), 1305-1329.

Corsi, F. (2009). A simple approximate long-memory model of realized volatility. Journal of Financial Econometrics, 7(2), 174-196.

Da, Z., Engelberg, J., \& Gao, P. (2011). In search of attention. The journal of finance, 66(5), 14611499.

Fama, E. F. (1976). Foundations of finance: portfolio decisions and securities prices: Basic Books (AZ).

Glosten, L. R., Jagannathan, R., \& Runkle, D. E. (1993). On the relation between the expected value and the volatility of the nominal excess return on stocks. The journal of finance, 48(5), 1779-1801. 
Hausman, J. A. (1978). Specification tests in econometrics. Econometrica: Journal of the econometric society, 1251-1271.

Joseph, K., Wintoki, M. B., \& Zhang, Z. (2011). Forecasting abnormal stock returns and trading volume using investor sentiment: Evidence from online search. International Journal of Forecasting, 27(4), 1116-1127.

Levin, A., Lin, C.-F., \& Chu, C.-S. J. (2002). Unit root tests in panel data: asymptotic and finitesample properties. Journal of econometrics, 108(1), 1-24.

Merton, R. C. (1987). A simple model of capital market equilibrium with incomplete information.

Moat, H. S., Curme, C., Avakian, A., Kenett, D. Y., Stanley, H. E., \& Preis, T. (2013). Quantifying Wikipedia usage patterns before stock market moves. Scientific reports, 3(1), 1-5.

Poon, S.H., \& Granger, C. W. (2003). Forecasting volatility in financial markets: A review. Journal of economic literature, 41(2), 478-539.

Preis, T., Reith, D., \& Stanley, H. E. (2010). Complex dynamics of our economic life on different scales: insights from search engine query data. Philosophical Transactions of the Royal Society A: Mathematical, Physical and Engineering Sciences, 368(1933), 5707-5719.

Takeda, F., \& Yamazaki, H. (2006). Stock price reactions to public TV programs on listed Japanese companies. Economics Bulletin, 13(7), 1-7.

Vlastakis, N., \& Markellos, R. N. (2012). Information demand and stock market volatility. Journal of Banking \& Finance, 36(6), 1808-1821. 